\title{
Estimating the size of key populations at higher risk of HIV infection: a summary of experiences and lessons presented during a technical meeting on size estimation among key populations in Asian countries
}

\author{
Dongbao Yu, ${ }^{a}$ Jesus Maria Garcia Calleja, ${ }^{b}$ Jinkou Zhao, ${ }^{c}$ Amala Reddyd and Nicole Seguy on behalf of the \\ participants of the Technical Consultation on Lessons Learnt from Size Estimation among Key Populations in \\ Asian Countries \\ Correspondence to Dongbao Yu (yud@wpro.who.int).
}

Problem: Size estimates of key populations at higher risk of HIV exposure are recognized as critical for understanding the trajectory of the HIV epidemic and planning and monitoring an effective response, especially for countries with concentrated and low epidemics such as those in Asia.

Context: To help countries estimate population sizes of key populations, global guidelines were updated in 2011 to reflect new technical developments and recent field experiences in applying these methods.

Action: In September 2013, a meeting of programme managers and experts experienced with population size estimates (PSE) for key populations was held for 13 Asian countries. This article summarizes the key results presented, shares practical lessons learnt and reviews the methodological approaches from implementing PSE in 13 countries.

Lessons learnt: It is important to build capacity to collect, analyse and use PSE data; establish a technical review group; and implement a transparent, well-documented process. Countries should adapt global PSE guidelines and maintain operational definitions that are more relevant and useable for country programmes. Development of methods for nonvenue-based key populations requires more investment and collaborative efforts between countries and among partners.

$\mathrm{P}$ opulation size estimates (PSE) for key populations at higher risk of HIV exposure, such as female sex workers (FSW), men who have sex with men (MSM) and people who inject drugs (PWID), are a crucial component of national HIV strategic planning, programme design and monitoring and evaluation (M\&E). PSE are key information for advocacy, setting targets for prevention, service delivery and estimating resource needs at national and subnational levels. ${ }^{1}$ To help countries measure key population sizes, global guidelines were updated in 2011 to reflect new technical developments and recent field experiences in applying these methods. ${ }^{2}$ National-level PSE are essential for epidemic models used to project the magnitude and trends of HIV epidemics and are key to building indicators required for programme M\&E. It is a priority of international technical agencies and development partners, including United Nations Programme on HIV/AIDS (UNAIDS), ${ }^{3}$ World Health Organization (WHO), the Global Fund to Fight AIDS, Tuberculosis and Malaria (Global Fund) ${ }^{4}$ and the United States President's Emergency Fund for AIDS Relief to encourage and support national AIDS programmes to collect and use these data.

PSE exercises for many countries comprise two phases: (1) local size estimation of key populations in a geographically specified area, and (2) extrapolation

\footnotetext{
HIV, Hepatitis and STI, World Health Organization Regional Office for the Western Pacific, Manila, Philippines.

HIV Department, World Health Organization, Geneva, Switzerland.

The Global Fund to fight AIDS, Tuberculosis and Malaria, Geneva, Switzerland

Joint United Nations Programme on HIV/AIDS, Regional Support Team for Asia and the Pacific, Bangkok, Thailand.

World Health Organization Representative Office in China, Beiijing, China.

Submitted: 5 May 2014; Published: 30 September 2014

doi: 10.5365/wpsar.2014.5.2.008
} 
Table 1. Population size estimation methods used and year conducted, reported by countries participating in the meeting

\begin{tabular}{|c|c|c|c|c|c|c|}
\hline Country & Key populations & $\begin{array}{l}\text { Mapping/census/ } \\
\text { enumeration }\end{array}$ & $\begin{array}{l}\text { Survey } \\
\text { multiplier }\end{array}$ & $\begin{array}{l}\text { Capturel } \\
\text { recapture }\end{array}$ & $\begin{array}{l}\text { Network } \\
\text { scale-up }\end{array}$ & $\begin{array}{l}\text { Other } \\
\text { methods }\end{array}$ \\
\hline Bangladesh & FSW, MSM, PWID & 2009 & 2004 & 2004 & - & 2010 \\
\hline Cambodia & PWID & 2012 & 2012 & 2012 & - & 2012 \\
\hline China & FSW, MSM, PWID & 2012 & - & - & 2012 (MSM) & 2012 \\
\hline India & FSW, PWID & Annually since 2007 & - & - & - & - \\
\hline Indonesia & FSW, MSM, PWID & 2012 & - & - & - & - \\
\hline $\begin{array}{l}\text { Lao People's Democratic } \\
\text { Republic }\end{array}$ & FSW, MSM, PWID & 2010 & - & - & - & - \\
\hline Malaysia & FSW, PWID & 2009 & 2009 & - & - & 2009 \\
\hline Mongolia & FSW & 2006 & - & - & - & - \\
\hline Myanmar & FSW & 2010 & - & - & - & - \\
\hline Nepal & FSW, MSM, PWID & 2011 & - & - & - & - \\
\hline Philippines & FSW, MSM, PWID & 2011 & - & - & - & 2011 \\
\hline Thailand & FSW, MSM, PWID & 2010 & 2010 & - & 2010 (PWID) & 2011 \\
\hline Viet Nam & FSW, MSM, PWID & 2011 & 2011 & 2011 & - & 2011 \\
\hline
\end{tabular}

Note: the years in the table denote the latest round.

FSW, female sex workers; MSM, men who have sex with men; PWID, people who inject drugs.

from areas with local size estimates to a regional or national level. The methodologies for local PSE range from direct observation and counting (i.e. census of entire populations or enumeration/mapping of selected subgroups or locations) to surveys or samples of key populations (i.e. service or unique object multiplier methods, capture/recapture with overlapping surveys of the same population) to surveys of the general population (i.e. network scale-up method or directly asking a behaviour among the general population). ${ }^{5}$

\section{CONTEXT}

Calculating the PSE for key populations most at risk of HIV remains challenging. Many people in these groups are highly mobile and may remain hidden due to fear of stigma, harassment and even prosecution. In addition, new technologies such as mobile phones and the Internet facilitate seeking clients and sex partners. To help countries address these challenges, global guidelines for estimating the size of key populations were updated in 2011 to reflect new technical developments and recent field experience in applying new methods. ${ }^{2}$ Due to the concentrated and low-level epidemics in Asia, estimating the size of key populations has been particularly important to measure the burden of HIV, track the epidemic and assess service coverage.

\section{ACTION}

From 24 to 25 September 2013, a meeting on PSE for key populations was held for 13 Asian countries. The meeting was organized by WHO with support from the UNAIDS Regional Support Team for Asia and the Pacific, the United States Centers for Disease Control and Prevention and the Global Fund. Programme managers and experts working in HIV surveillance, monitoring and evaluation with experience in implementing PSE were nominated by the ministries of health from Member States. Experts from partner agencies were invited to participate and facilitate discussions. Each participant was invited to present the PSE work conducted in each respective country. Presentations focused on methodology, results, lessons learnt and use of data. A panel discussion summarized the major findings, methodological issues, data use, challenges and next steps for implementation of PSE in the region (Table 1).

\section{Coordination}

In most of the countries, data collection was coordinated centrally by national AIDS programmes and their partners. These partners included civil society organizations implementing targeted interventions; national research 
Table 2. Duplication-adjustment methods

\begin{tabular}{|c|c|c|}
\hline Country & Key population group & Method of duplication calculation \\
\hline Bangladesh & MSM & $\begin{array}{l}\text { During census/enumeration MSM were asked leaving and entering hotspots where they } \\
\text { were going to and/or coming from. }\end{array}$ \\
\hline India & FSW, MSM, PWID & Patterns of mobility were asked of key informants during mapping. \\
\hline Nepal & FSW, MSM, PWID & $\begin{array}{l}\text { Key informants were asked about number of hotspots typically visited by key population } \\
\text { during mapping, averaged and adjusted at national level. }\end{array}$ \\
\hline Thailand & FSW & $\begin{array}{l}\text { Service providers estimated the overlap in coverage in Bangkok. Estimated } 20 \% \text { overlap } \\
\text { in large district; } 10 \% \text { overlap in small district. }\end{array}$ \\
\hline Viet Nam & FSW, MSM, PWID & $\begin{array}{l}\text { Respondents were asked whether they had visited multiple sites during key population } \\
\text { surveys. }\end{array}$ \\
\hline
\end{tabular}

FSW, female sex workers; MSM, men who have sex with men; PWID, people who inject drugs.

\section{Table 3. Inflation factors to account for hidden or non-venue-based subgroups}

\begin{tabular}{llll}
\hline \multicolumn{1}{c}{ Country } & Key population group & \multicolumn{1}{c}{ Basis of inflation factor } & \multicolumn{1}{c}{ Inflation factor used } \\
\hline Indonesia & MSM & $\begin{array}{l}\text { \% of MSM survey respondents who were not } \\
\text { exposed to intervention }\end{array}$ & $\begin{array}{c}5,5.9,11.8 \mathrm{X} \text { (depending on type } \\
\text { of district) }\end{array}$ \\
Malaysia & FSW & Not given & $2 \mathrm{X}$ \\
Myanmar & FSW & Not given & $1.4 \mathrm{X}$ \\
Nepal & PWID & Not given & PWID: $1.4 \mathrm{X}$ \\
Thailand & FSW, MSW & Expert opinion & FSW: $1.82 \mathrm{X}$ \\
& & MSW: $2.18 \mathrm{X}$ \\
Viet Nam & PWID & Police estimate of \% of drug users that they track & $1.4 \mathrm{X}$ \\
\hline
\end{tabular}

FSW, female sex workers; MSM, men who have sex with men; PWID, people who inject drugs.

institutes; and local offices for narcotics control, social hygiene and/or police.

\section{Methods commonly used}

All 13 countries mapped venues and/or locations that key populations frequented with subsequent sampling/ enumeration to obtain sizes of FSW and MSM (Table 1). ${ }^{1}$ Five countries applied the survey-based multiplier either using exposure to prevention services or distributing unique objects. ${ }^{1}$ Three countries reported their work on capture/recapture, and two countries shared results from network scale-up studies. ${ }^{6}$ Many countries commented on the inadequacy of the methods available for capturing important non-venue-based subgroups, such as homebased sex workers, MSM and sex workers who meet partners/clients via the Internet or mobile phones. ${ }^{7}$

\section{Methodological innovations}

Countries reported on the following methodological innovations developed to customize global PSE:

\section{Validation of census enumeration results}

India assigned a proportion of hotspots which were mapped by two independent field teams. Results were compared and when found to be inconsistent, remapping of a broader area was undertaken. In Nepal, two independent mapping teams compared and validated the number of hotspots in a sample of districts.

\section{Duplication adjustment methods}

The mobile nature of most key populations often results in double counting individuals in different venues. Methods for duplication adjustment are described in Table 2.

\section{Adjustments for hidden or non-venue-based key population subgroups}

Inflation factors were developed to adjust the data from venue-based methods (e.g. census/enumeration, capture/recapture, or survey-based multipliers using time-location sampling) to include the non-venue-based 
Table 4. Examples of extrapolation methods by countries participating in the meeting

\begin{tabular}{llc}
\hline \multicolumn{1}{c}{ Country (KP) } & \multicolumn{1}{c}{ Extrapolation approaches } & Number of categories* \\
\hline India (PWID) & Urban and rural areas & 2 \\
Indonesia & Using regression models to predict size at district level & $450+$ \\
Malaysia (PWID) & States grouped by addiction severity & 3 \\
Myanmar (FSW) & Townships grouped by epidemiological characteristics & 4 \\
Nepal & Matching districts by epidemiological zone & 6 \\
Philippines (FSW) & Capital and area outside of capital & 2 \\
Thailand (MSM) & Extrapolation by regions and capital & 5 \\
\hline \multirow{2}{*}{ * Category is defined according to the HIV epidemics at the subnational level, as determined by the social-economic, demographic and } \\
epidemiological factors of geographic areas. \\
FSW, female sex workers; KP, key population; MSM, men who have sex with men; PWID, people who inject drugs.
\end{tabular}

group (Table 3). Inflation factors in Indonesia were based on survey samples obtained from respondentdriven sampling $(\mathrm{RDS})^{8}$ surveys that were believed to be more representative of the non-venue-based key population. ${ }^{9}$ The proportion of respondents who reported not frequenting venues formed the basis of the inflation factors.

Other countries (e.g. Viet Nam and Nepal) used key population survey data on the proportion of respondents who were not reached by interventions as the inflation factor. This adjustment assumes that the key population surveys, from which intervention coverage data are derived, are representative of those who prefer not to be hidden, either because of incentives to participate in the survey or because recruitment was done by trusted peers as in the case of RDS.

\section{Other adjustments}

Two other adjustments were developed in Nepal and also appeared in the Viet Nam national size estimation protocol to improve the accuracy of the PSE. ${ }^{10,11}$ The first was an adjustment for frequency of visiting venues, ${ }^{12}$ taking into account that those who visited less frequently (e.g. once or twice a month) might be underestimated. An additional adjustment was made to account for turnover in a population, defined as the rate at which members of the key population leave the local area or stop the population-defining risk behaviour (e.g. women who stop selling sex).

\section{Extrapolation strategies}

All countries, except those using national network scaleup in surveys, extrapolated data from areas with local PSE to the national level. This is generally the proportion of the key population compared to the entire adult male or female population in areas with local data and forms the basis of the proportion applied to national or subnational adult populations. Due to the diversity of key populationdriven epidemics at the subnational level, countries have attempted to refine this extrapolation method by applying different proportions to different geographic areas (Table 4). Indonesia presented regression models to predict district-level key PSE based on several sociocultural-economic variables available from a national survey conducted every three years. ${ }^{13}$ This best-fit regression model used size estimates, generated through census/enumeration from approximately half of the country's districts, as the outcome variable.

\section{Developing ranges for size estimates}

Due to the inherent imprecision associated with size estimation, most countries present a range of values for national- and subnational-level PSE and vary in their approaches for setting these boundaries (Table 5). In many countries, multiple sources of size estimates data are triangulated to obtain a final consensus range agreed upon by national stakeholders, technical experts and key population groups. In other countries, a single data source is selected as the most valid estimate, believed to be the 
Table 5. Approaches to developing upper and lower bounds on national size estimates

\begin{tabular}{|c|c|c|c|}
\hline Country & Group(s) & Method for determining range & Range of national estimate \\
\hline Bangladesh & MSM & $\begin{array}{l}\text { Lower value based on mapping counts; higher value based } \\
\text { on expert consultation }\end{array}$ & 32 000-143000 \\
\hline Cambodia & PWID & $\begin{array}{l}\text { Lowest and highest results of different survey-based multi- } \\
\text { pliers }\end{array}$ & $10000-28000$ \\
\hline India & PWID & $\begin{array}{l}\text { Median absolute deviation between mapped result and key } \\
\text { population intervention targets }\end{array}$ & 68 000-132000 \\
\hline Indonesia & $\begin{array}{l}\text { FSW, MSM, } \\
\text { PWID }\end{array}$ & $\begin{array}{l}\text { Confidence interval calculated on the basis of district-level } \\
\text { estimates produced by regression model }\end{array}$ & $\begin{array}{l}\text { FSW: } 180000-260000 \\
\text { MSM: 0.9-1.2 million } \\
\text { PWID: } 60000-80000\end{array}$ \\
\hline Malaysia & PWID & $\begin{array}{l}\text { Low and high values based on multiplier data collected from } \\
\text { drug users versus other key informants. }\end{array}$ & $80000-156000$ \\
\hline Nepal & FSW & $\begin{array}{l}\text { Low and high values based on key informant estimates } \\
\text { from mapping }\end{array}$ & $24000-28000$ \\
\hline Philippines & MSM & $\begin{array}{l}\text { Low and high values based on range of different survey } \\
\text { results }\end{array}$ & $390000-689000$ \\
\hline Myanmar & FSW & Range based on key informant estimates during mapping & $35000-73000$ \\
\hline Thailand & PWID & $\begin{array}{l}\text { Low and high value based on network scale-up result and } \\
\text { summation result from national general population survey }\end{array}$ & $40000-93000$ \\
\hline
\end{tabular}

FSW, female sex workers; MSM, men who have sex with men; PWID, people who inject drugs.

correct estimate relative to others, with upper and lower boundaries based on a statistical calculation relevant to the method used. ${ }^{1}$ Technical advisers involved in the PSE process often use regional or global benchmarks to ensure the range is a plausible proportion of the general population. Most countries presenting their results at the meeting presented a large range, with upper bounds more than double the minimum estimates. Moreover, the methods used for estimating ranges are not standardized among countries.

\section{KEY LESSONS LEARNT}

\section{Developing country-specific protocols and local capacity}

Country representatives emphasized the importance of adapting global PSE guidelines for local contexts. Operational definitions used for different key populations varied considerably by country. Maintaining countryspecific operational definitions that resulted in data that were more relevant and useable for country programme planning was felt to outweigh the challenges such differences pose to making intercountry comparisons.

Several countries described the importance of conducting multiple rounds of size estimation for refining methods and obtaining more precise results. This has assisted in expanding local capacity for collecting data, standardizing approaches and using multiple methods to triangulate data. Several countries such as China and India described a significant investment of resources to update local size estimates on a regular basis, which is particularly important for large countries with diverse epidemics. It is important that before initiating surveys, key populations have been provided with services and recorded at service delivery facilities to collect information on unique visits. ${ }^{6}$

\section{Using PSE data and engaging stakeholders}

Optimizing the use of PSE for programme planning and resource allocation requires different stakeholders to have consensus about the final estimate. Many countries reported the importance of engaging stakeholders in a transparent process for data collection, application of adjustments and extrapolation of results which was achieved through documentation, technical expert review and community engagement in all stages of the process. Representatives also recognized the need for multiple estimates. Thailand reported using a broad definition of MSM in their size estimates exercises but determined about $30 \%$ of the total MSM community were high risk and focused on the size of this subgroup to allocate resources for HIV prevention services for MSM. 
Ongoing challenges for estimates of key subgroups and non-venue-based populations

Participants advocated for separate estimates for the transgender population and male sex worker subgroups as critical for developing more effective local prevention programmes. Countries continue to struggle to estimate the size of populations who prefer to be hidden due to stigma, discrimination and punitive laws or who are changing their behaviour patterns. This issue has been a long-standing challenge for MSM and PWID groups but may be increasingly relevant for subgroups such as home-based FSW.

\section{DISCUSSION AND RECOMMENDATIONS}

This paper reviews recent PSE activities for key populations in 13 Asian countries. The authors recognize that not all Asian countries were represented at the meeting, and it was not feasible for country representatives to present a comprehensive overview of all PSE activities to date. Instead, this report focuses primarily on information presented at the meeting, supported with published literature.

Many countries in the region have accumulated valuable experience in adapting PSE methods to meet challenging contexts. However, some countries participating in the meeting continue to rely on expert opinions or regional benchmarks rather than data collected via recommended methods. Countries that have applied multiple methods for the same key population in the same geographic areas often face the challenge of resolving large discrepancies. The quality of size estimation is of concern for some countries. Greater resources with good technical assistance should be spent on triangulating these data and distinguishing between expected differences due to methodological limitations, poor implementation and large fluctuations in size of particular key populations. Due to the complexity of interpreting PSE for key populations, establishing a consistent technical review group of experts to analyse, document and disseminate PSE results is critical for using key PSE to strengthen a country's AIDS response. Finally, considering the high cost involved in a standalone PSE exercise, countries are encouraged to integrate it with other ongoing activities and surveys.
Participating countries strongly support efforts to develop local solutions to refine the available methods and have requested that development partners facilitate opportunities to share good practices. One promising proposal is the successive sampling size method ${ }^{14}$ recently introduced at a UNAIDS meeting of PSE techniques for hard-to-reach populations in October 2013. Recommendations made during the meeting included the mobilization of resources from governments, technical partners and funding agencies which could include the consideration of PSE in the development of the concept note for the Global Fund's new funding mode. ${ }^{15}$ Efforts should also be made to consolidate and disseminate information from different countries related to their experiences in adjustments for hidden subgroups and extrapolation from local to national levels. Most importantly, PSE should be planned, implemented and directly linked with programming.

\section{Participants of the meeting}

The following participants attended and contributed to the meeting:

Dr Md Anisur Rahman, Dr Ly Penh Sun, Dr Hong Hu, Dr Houlin Tang, Professor Kuntoro, Ms Viny Sutriani, Dr Keophouvanh Douangpachanh, Dr Fazidah Binti Yuswan, Dr Mohd Nasir Abudul Aziz, Dr Zayasaikhan Setsen, Dr Ko Ko Naing, Dr Kyaw Soe, Mr Noel S Palaypayon, Dr Panithee Thammawijaya, Professsor Apinun Aramrattana, Mr Nguyen Long Duc, Dr Tran Quang Dai, Dr Abu S Abdul-Quader, Dr Bui Hoang Duc, DrYi Chen, Dr Jonathan Neil V Erasmo, Dr Wolfgang Hladik, Dr DCS Reddy, Dr SK Singh, Dr Heng Sopheab, Dr Guohui Wu, Professor Joseph Irvin Harwell, Assistant Professor Huso Yi, Professor Mo Kit Han Phoenix, Dr Zixin Wang, Dr Kin Ho Philip Wong, Mr Daniel Low-Beer, Dr Jinkou Zhao, Dr Dongbao Yu, Dr Nicole Seguy, and Dr Jesus Maria Garcia Calleja.

We also would like to acknowledge the assistance and contribution of Virginia Loo, Ying-Ru Lo, Amaya Maw Naing and Laximi Achaya.

\section{Funding}

None. 


\section{Conflict of interest}

None declared.

\section{References}

1. Consolidated guidelines on HIV prevention, diagnosis, treatment and care for key population. Geneva, World Health Organization, $2014 \quad$ (http://apps.who.int/iris/ bitstream/10665/128048/1/9789241507431 eng. pdf?ua $=1 \&$ ua $=1$, accessed 29 September 2014).

2. UNAIDS, WHO Working Group on Global HIV/AIDS and STI Surveillance. Guidelines on Estimating the Size of Populations Most at Risk to HIV. Geneva, World Health Organization and UNAIDS, $2010 \quad$ (http://www.unaids.org/en/media/unaids/ contentassets/documents/epidemiology/2011/2011_estimating populations_en.pdf, accessed 29 September 2014).

3. 2010-2011 UNAIDS UBW Broad Activity Achievement Report. Geneva, The Joint United Nations Programme on HIV/AIDS, 2012 (http://www.unaids.org/en/media/unaids/contentassets/ documents/document/2012/ubw2010-2011/Secretariat 20102011BAReport.pdf, accessed 29 September 2014).

4. Global Fund HIV Proposal Development for Key Population Proposals and for the Targeted Pool in Round 11: Toolkit. Geneva, The Joint United Nations Programme on HIV/AIDS, 2011.

5. Abdul-Quader AS, Baughman AL, Hladik W. Estimating the size of key populations: current status and future possibilities. Current Opinion in HIV and AIDS, 2014, 9:107-114. doi:10.1097/ COH.0000000000000041 pmid:24393694

6. Johnston LG et al. Incorporating the service multiplier method in respondent-driven sampling surveys to estimate the size of hidden and hard-to-reach populations: case studies from around the world. Sexually Transmitted Diseases, 2013, 40:304-310. doi:10.1097/OLQ.0b013e31827fd650 pmid:23486495
7. Li $\mathrm{Q}$ et al. Online sex-seeking behaviors among men who have sex with men: implications for investigation and intervention. AIDS and Behavior, 2012, 16:1690-1698. doi:10.1007/s10461011-0005-0 pmid:21785872

8. Hechathorn D. Respondent-driven sampling: A new approach to the study of hidden populations. Social Problems, 1997, 44:174198. doi: $10.1525 / \mathrm{sp} .1997 .44 .2 .03 \times 0221 \mathrm{~m}$

9. Kendall $\mathrm{C}$ et al. An Empirical Comparison of Respondent-driven Sampling, Time Location Sampling, and Snowball Sampling for Behavioral Surveillance in Men Who Have Sex with Men, Fortaleza, Brazil. AIDS and Behaviour, 2008, 12(1): Suppl 97-104.

10. HIV/AIDS and STI Control Board \& National Centre for AIDS and STD Control. Mapping \& Size Estimation of Most-at-riskpopulation in Nepal, 2011. Katmandu, National Centre for AIDS and STD, 2011, Volumes 1-4.

11. Size Estimation of Injecting Drug Users, Commercial Sex Workers, and Men Who Have Sex with Men in Vietnam. Vientiane, National Institute of Hygiene and Epidemiology, 2010.

12. Karon JM, Wejnert C. Statistical methods for the analysis of timelocation sampling data. Journal of Urban Health, 2012, 89:565586. doi:10.1007/s11524-012-9676-8 pmid:22421885

13. 2012 Size Estimation of Key Affected Populations. Jakarta, Ministry of Health Indonesia, 2013.

14. Handcock MS, Gile KJ, Mar CM. Estimating Hidden Population Size using Respondent-Driven Sampling Data. arXiv: 1209.6241 [stat.ME]. (http://arxiv.org/pdf/1209.6241v1.pdf, accessed 29 September 2014).

15. Roll out of the new funding model and Technical Assistance Special Initiative. Global Fund Regional Meeting, 8-9 April 2014,Kingston, Jamaica. Geneva, The Global Fund to Fight AIDS, Tuberculosis and Malaria, 2014 (http://www.theglobalfund. org/documents/regional_meetings/2014-04-08-Jamaica/ Events_2014-04-08-R-M-LAC-TechnicalAssistanceSpeciallnitiati ve_Presentation_en/, accessed 29 September 2014). 